\title{
DEBATES
}

\section{Lei é lei? Maurice Duverger e as eleições para o Senado no Brasil}

\author{
Law is law? Maurice Duverger and the Senate election in Brazil
}

\author{
José Alexandre da Silva Júnior \\ Willber Nascimento \\ Albany Ferreira Lima \\ Widyane da Silva Omena
}

\begin{abstract}
Resumo
Qual o efeito da magnitude sobre o Número Efetivo de Partidos (NEP) da eleição para o Senado brasileiro? Este artigo analisa a relação entre os sistemas eleitoral e partidário no Brasil. Especificamente, testamos a hipótese de que a magnitude exerce um efeito positivo e significativo sobre o número efetivo de partidos. Acreditamos que as eleiçóes para o Senado são um bom laboratório para testar as proposiçóes de Duverger porque mantêm a fórmula eleitoral, mas permitem uma alternância na magnitude. Metodologicamente, analisamos dados do Tribunal Superior Eleitoral (TSE) referentes às seis últimas eleiçôes (1998-2018). Utilizamos técnicas de estatística descritiva e inferencial para estimar o efeito da magnitude controlando por outras variáveis. Os principais resultados apontam que: 1) a magnitude exerce um efeito positivo e significativo no NEP; 2) o equilíbrio duvergeriano é mais frequente em eleiçôes de um terço; 3) eleiçôes simultâneas exercem um efeito significativo no NEP.
\end{abstract}

\section{Palavras-chave}

Lei de Duverger; Número Efetivo de Partidos; Magnitude dos Distritos; Senado Brasileiro; Partidos Políticos.

\begin{abstract}
What is the effect of the magnitude in the Effective Number of Parties (NEP) of the election for Brazilian Senate? This paper analyzes the relationship between the electoral and partisan systems in Brazil. Specifically, we test the hypothesis that magnitude has a positive and significant effect on the effective number of parties. We believe that Senate elections are a good laboratory to test Duverger's propositions because they maintain the electoral formula but allow for a switch in magnitude. Methodologically, we analyzed data from the Superior Electoral Court (TSE) for the last six elections (1998-2018). We used descriptive and inferential statistical techniques to estimate the magnitude effect, controlling for some other variables. The main results indicate that: 1) the magnitude has a positive and significant effect on the NEP; 2) the Duvergerian balance is more frequent in elections of one third; 3) concurrent elections have a significant effect on the NEP.
\end{abstract}

\section{Keywords}

Duverger Law; Effective Number of Parties; District Magnitude; Brazilian Senate; Political Parties. 


\section{Introdução}

Há quase setenta anos, Maurice Duverger anunciou as bases de uma das poucas leis da Ciência Política. Duverger (1970) verificou a existência de uma relação quase inexorável entre modelos de sistemas eleitorais e o número de partidos a partir da observação sistemática de um conjunto de democracias predominantemente europeias. Segundo Riker (1982), as investigaçóes sobre essa relação constituem um exemplo raro de acúmulo de conhecimento na Ciência Política. Nesse sentido, “[...] acúmulo de conhecimento significa que não apenas o corpus de proposições está crescendo, mas também que cada uma das revisões é mais geral e mais precisa que a anterior" (RIKER, 1982, p. 753) ${ }^{1}$.

$\mathrm{Na}$ contramão, os estudos sobre os sistemas eleitoral e partidário brasileiros não primaram por verificar a aplicação da Lei de Duverger. Para Lima Júnior (1997), essa ausência é resultado do foco dos estudos partidários brasileiros nas eleiçóes parlamentares. Como nesse âmbito utiliza-se a representação proporcional, reduz-se o espaço para o debate sobre o efeito das regras eleitorais no número de partidos (LIMA JÚNIOR, 1997; GUARNIERI, 2015).

Este trabalho tenta reduzir esse gap e analisa a relação entre os sistemas eleitoral e partidário a partir das eleições para o Senado brasileiro. A questão de pesquisa é: qual o efeito da magnitude sobre o Número Efetivo de Partidos (NEP) da eleição para o Senado brasileiro? A hipótese de trabalho é que a magnitude exerce um efeito positivo e significativo sobre o NEP. Apostamos que esse tipo de pleito é um bom laboratório para testar as proposiçôes de Duverger (1970) porque mantém a fórmula eleitoral e determina uma alternância na magnitude (dobra e reduz pela metade na sequência dos pleitos). Basicamente, apostamos que tanto o efeito mecânico quanto o psicológico "entram em campo", reduzindo o NEP em pleitos em que a magnitude é menor, mesmo com a manutenção da fórmula. Em tese, o modelo de maioria simples utilizado para o Senado brasileiro tenderia a gerar um sistema bipartidário. A intenção é estender as proposiçôes de Duverger (1970) e mostrar que a presença de eleiçôes simultâneas e, principalmente, a alternância da magnitude podem ser obstáculos fortes a esse prognóstico (TAAGEPERA e SHUGART, 1989; SHUGART e CAREY, 1992). Aqui testamos o efeito da magnitude controlando, em alguma medida, a simultaneidade das eleições. Para tanto, analisamos os dados das

\footnotetext{
1 Tradução Livre de: "[...] accumulation of knowledge" we mean not only that the corpus of propositions is growing, but also that each one of the series of revisions is more general or more precise than its predecessor" (RIKER, 1982, p. 753).
} 
eleições para o Senado no período 1998-2018. Precisamente, combinamos estatística descritiva e inferencial para estimar esse efeito.

O trabalho está organizado em quatro seções além desta introdução. $\mathrm{Na}$ primeira, apresentamos a Lei de Duverger e o seu impacto. Na segunda, a discussão foca o número efetivo de partidos (NEP). A seção seguinte traz os detalhes sobre a metodologia e apresenta os principais resultados. Por fim, expomos as consideraçóes finais.

\section{A Lei de Duverger}

Munido de um espírito raro na Ciência Política, Duverger (1970) anunciou a criação de uma lei baseado em duas proposiçôes básicas: 1) eleição por maioria simples favorece o bipartidarismo e 2) sistemas majoritários de dois turnos ou proporcionais favorecem o multipartidarismo (DUVERGER, 1970). Essas sentenças baseiam-se em dois mecanismos específicos: 1) mecânico e 2) psicológico. O efeito mecânico corresponde à sub-representação dos partidos perdedores. Em geral, esse efeito tende a beneficiar os partidos maiores, com maior número de cadeiras. Portanto, em longo prazo, espera-se que os políticos abandonem os partidos perdedores para maximizar a sua chance de vitória. Na literatura, a maioria dos testes dessa relação demostra que a regra de maioria simples é significativamente menos favorável aos partidos menores (DUVERGER, 2003; RIKER 2003; GRUMM, 1958; TUFTE 1973). Como notam Nicolau e Schmitt (1995), a sub-representação é um efeito direto da fórmula de disputa. Ela cresce na medida em que se reduz o número de vagas (DUVERGER, 1970). Entretanto, a redução do número de partidos é uma consequência dessa dinâmica reforçada pelo cálculo racional dos políticos (RIKER, 2003).

O efeito psicológico é a tendência de o eleitor votar em candidatos com maior chance de vitória. Para Duverger (1970), racionalmente o eleitor tenta "salvar" seu voto apostando em candidatos com menor chance de serem derrotados. O número de vagas tem efeito sobre esse cálculo/percepção². Segundo Riker (2003), o grande desafio do efeito psicológico é mostrar como o eleitor compatibiliza o cálculo da probabilidade de vitória com o da utilidade esperada do voto. Riker (1982)

\footnotetext{
2 Segundo Nicolau e Schimitt (1995), o efeito psicológico também incide sobre os dirigentes partidários. Faz parte das estratégias de campanha uma projeção sobre a influência do efeito mecânico nas chances eleitorais dos candidatos.
} 
argumenta que a grande "pedra no sapato" do efeito psicológico é o conceito de sofisticação do voto criado por Downs (1999).

Em outros termos, o desafio do eleitor é identificar simultaneamente qual o partido que lhe traria o melhor retorno e quais deles têm chances reais de vitória (DOWNS, 1999). A questão é que nem sempre o eleitor está capacitado ou interessado em sofisticar seu voto. Por exemplo, a existência de um terceiro partido em países como a Inglaterra deve-se à utilidade esperada do voto (RIKER, 1982). O voto no partido liberal muitas vezes não está associado à maior chance de vitória nacionalmente, mas à preferência do eleitor ${ }^{3}$. Isso explicaria a existência de três partidos, mesmo em um país que usa a regra de maioria simples para escolher os representantes políticos (RIKER, 1982).

Repare que "[...] ao contrário do mecânico, o efeito psicológico precisa de pelo menos duas eleiçóes para ocorrer” (NICOLAU e SCHMITT, 1995, p. 132). Ou seja, o efeito mecânico incide sobre a distribuição das cadeiras, e o psicológico afeta a distribuição dos votos (NICOLAU e SCHMITT, 1995). Para Lijphart (1994), é importante identificar a dimensão do sistema eleitoral afetada por cada efeito. $\mathrm{O}$ efeito psicológico afeta unicamente o número de partidos efetivos no sistema eleitoral. Já o mecânico afeta também o número efetivo de partidos no parlamento pelo processo de transformação de votos em cadeiras (LIJPHART, 1994). Na prática, o eleitor identifica os candidatos viáveis antes de oferecer seu voto, isso reduz o número efetivo de opções.

A etapa seguinte é a transformação desses votos em cadeiras, o que tem impacto sobre a fragmentação do resultado do pleito (LIJPHART, 1994). Segundo Nicolau e Schmitt (1994), a relação prevista por Duverger (1970) entre o sistema de maioria simples e o bipartidarismo deve ser observada através dos efeitos psicológico e mecânico. Em termos operacionais, isso significa que se deve analisar a oscilação do número de candidatos/partidos efetivos considerando as eleiçóes aos pares, assim como se deve examinar a quantidade de votos conferidos a candidatos que não alcançaram sucesso.

\footnotetext{
${ }^{3}$ De acordo com Downs (1999), os eleitores não revelam exatamente as suas preferencias a partir do voto. A decisão sobre em quem votar é resultado do retorno esperado e a chance de vitória do candidato.
} 


\section{O impacto da Lei}

De acordo com Cox (1997), as reaçôes ao trabalho de Duverger (1970) concentram-se em dois aspectos: 1) no grau de comparação e 2) na validade da relação. Os argumentos apresentados por Sartori (1985) resumem as críticas ao primeiro aspecto. Segundo Sartori (1994, p. 30), “[...] é impossível alcançar validade

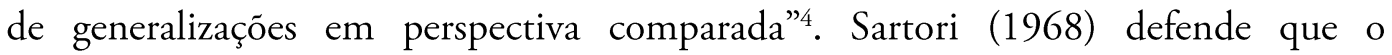
bipartidarismo estimado por Duverger (1970) depende da existência de partidos bem estruturados. Portanto, necessita de partidos com nível de organização estável e extensiva ao território nacional, assim como requer a presença de partidos com conteúdo ideológico reconhecido pelo eleitorado (SARTORI, 1968).

Quanto maior o respeito a essas condiçôes, maior seria o efeito da maioria simples sobre o número de partidos efetivos. Para Sartori (1968), o sistema de maioria simples seria uma condição suficiente para causar a eliminação de qualquer partido; portanto, permite a existência de tantos partidos quantos forem os que conseguirem a maioria simples de voto de qualquer distrito. Nesse caso, a relação entre a regra eleitoral e o número de partidos dependeria de uma medida contínua do nível de estruturação do sistema partidário.

Contrário a essa perspectiva, Riker (1982) defende Duverger (1970) a partir da classificação das suas proposições em duas categorias: 1) lei e 2) hipótese. Segundo Riker (1982), em sistemas majoritários os partidos procuram ampliar seu leque de representação a fim de conquistar o maior número de votos possível. Portanto, é racional esperar que os competidores visem conquistar mais da metade do eleitorado. Devido a essa tendência, é razoável esperar que o sistema se torne bipartidário. Contrariamente, "[...] quando a definição do vencedor não requer a maximização dos votos (como nas eleiçóes proporcionais) então o motivo para o bipartidarismo está ausente" (RIKER, 1982, p. 755)5. Em outros termos, em eleições proporcionais, o mecanismo que estabelece a relação entre o sistema eleitoral e o número efetivo de partidos simplesmente deixa de existir. Com isso, a relação entre ambos se torna incerta.

Por outro lado, a crítica quanto à validade ataca a relevância da variável número de partidos. Segundo Cox (1997), os "deterministas sociais” defendem a

\footnotetext{
4 Tradução livre de: “That comparatively valid generalizations are impossible to achieve." (SARTORI, 1994, p. 30).

5 Tradução Livre de: "When the definition of winning does not require them to maximize votes (as in runoff and proportional systems), then this motive for two parties is absent." (RIKER, 1982, p. 755).
} 
centralidade das clivagens sociais. De acordo com essa escola, o número de partidos é uma variável secundária, derivada do número e da intensidade das clivagens presentes na sociedade (COX, 1997). Portanto, o multipartidarismo seria resultado da existência de fortes clivagens sociais. A prova disso seria a presença desse tipo de sistema partidário em algumas democracias europeias que utilizam a regra de maioria simples em distritos multinominais (LIPSET e ROKKAN, 1967; ROKKAN, 1970).

Contrário à essa perspectiva, Cox (1997) e Shugart e Carey (1992) argumentam que as regras eleitorais têm um efeito independente e consistente no sistema partidário. Segundo Cox (1997), o efeito dos sistemas majoritários pode ser mostrado na redução do número de partidos. A redução do número de partidos seria uma função do processo de coordenação. Por coordenação entende-se "[...] ações primordialmente instrumentais em oposição aquelas que são irrefletidas" (COX, 1997, p. 149) ${ }^{6}$. Cox (1997) acredita que a decisão de lançar um candidato está baseada fundamentalmente na expectativa de vitória. Portanto, o efeito da fórmula eleitoral sobre o número de partidos depende do nível de competitividade do sistema. De acordo com Cox (1997), o equilíbrio no número de candidatos depende da formação de preferência e, principalmente, da expectativa de desempenho eleitoral entre os oponentes. Dessa forma, é possível designar um limite superior de equilíbrio do número de candidatos (ou listas) para qualquer sistema.

Para Cox (1997), caso o número real esteja longe do estimado, há uma tendência de aproximação. $\mathrm{O}$ chamado equilíbrio duvergeriano de $\mathrm{M}+1$, em que $\mathrm{M}$ corresponde à magnitude do distrito, seria verificado pela diferença entre o primeiro e segundo perdedor. Quanto maior a diferença, mais próximo do equilíbrio estaria o sistema (COX, 1997). Adicionalmente, Shugart e Carey (1992) argumentam que o número de partidos no sistema sofre influência direta da realização de eleições simultâneas. Para eles, a magnitude dos distritos e os ciclos eleitorais são variáveischave para analisar a relação entre os sistemas partidário e eleitoral. Shugart e Carey (1992) são pioneiros ao mostrar um efeito estruturante da disputa presidencial majoritária de turno único. De acordo com eles, o número de partidos vitoriosos no pleito proporcional é reduzido por conta da disputa presidencial ${ }^{7}$.

\footnotetext{
${ }^{6}$ Tradução Livre de: "Refers to actions that are primarily instrumental as opposed to consummatory" (COX, 1997, p. 149).

7 Até pouco tempo, o debate sobre o sistema partidário brasileiro apoiou-se em ideia semelhante (MELO e CÂMARA, 2012). Segundo Mair (2006), a parte mais importante do sistema partidário é constituída pela sua estrutura de competição.
} 


\section{O Número Efetivo de Partidos (NEP)}

Segundo Laakso e Taagepera (1979), antes de observar o efeito do número de partidos sobre a estabilidade do sistema político, é preciso aprender a contá-los levando em conta seu tamanho relativo. O número efetivo de partidos (NEP) é uma medida síntese da força relativa dos partidos no sistema eleitoral. Nesse caso, "efetivo" significa ter impacto sobre a fragmentação do sistema considerando a desigualdade ente as suas unidades (LAAKSO e TAAGEPERA, 1979). Precisamente, a medida é obtida pela divisão de 1,00 pelo somatório das proporções de votos ou cadeiras conquistadas pelos partidos em uma eleição:

$$
\begin{gathered}
\mathrm{NEP}=1 / \sum_{i=1}^{\infty} P_{i}^{2} \\
\text { Em que, } P=\text { proporçãodevotosválidos. }
\end{gathered}
$$

Dessa forma, quanto maior o quociente, maior o número efetivo de partidos. Porém, é preciso alguns cuidados na interpretação da medida (MOLINAR, 1991; GOLOSOV, 2010). Primeiro, ela depende da variável utilizada para a realização do cálculo. Caso seja utilizada a proporção de votos, a medida corresponde ao nível de fragmentação do sistema partidário. Em geral, costuma-se dimensionar também a competição eleitoral a partir desse mesmo resultado (SILVA, 2013; CARAMANDI, 2003). Porém, se a medida for calculada com base no percentual de cadeiras, refletirá a fragmentação da Casa correspondente à disputa ${ }^{8}$. Além de trocas na base de cálculo, também é comum registrar alterações na unidade de análise (LIJPHART, 2003). Precisamente, é muito comum na literatura o cálculo do chamado número efetivo de candidatos (NEC). De acordo com Lijphart (2003), em qualquer disputa em que os votos não sejam dados em listas, é possível dimensionar a competição a partir do NEC. Uma consequência importante disso é a possibilidade de dimensionar a competição intrapartidária (LIJPHART, 2003; NICOLAU, 2012).

O desafio maior na interpretação da medida está numa tendência ao falso cognato'. Por exemplo, numa situação em que sete partidos disputam uma eleição e registram os percentuais $55 \%, 8 \%, 7 \%, 8 \%, 8 \%, 6 \%$ e $8 \%$ com NEP $=2.93$, o leitor da medida tende a acreditar que os dois ou, se for generoso, os três maiores partidos

\footnotetext{
${ }^{8}$ Refere-se a "Casa" porque normalmente esse procedimento é utilizado para medir a fragmentação do Legislativo, seja ela na Câmara ou no Senado.

${ }^{9}$ Tomamos esse conceito emprestados da linguística.
} 
são de fato efetivos. Porém, há uma série de falhas nesse raciocínio. Primeiro, a medida não diz nada sobre que partidos são efetivos, é apenas um cálculo de probabilidade baseado na distribuição dos votos. Afinal, qual dos quatro partidos com $8 \%$ de votos constituiriam o segundo e/ou terceiro partidos efetivos? Mais que isso, o resultado $\mathrm{NEP}=2.93$ não tem decodificação direta no número de partidos. $\mathrm{Na}$ verdade, o NEP é uma medida síntese da distribuição do percentual de votos entre todos os partidos que participaram da disputa. Golosov (2010) faz a crítica ao NEP apontando principalmente alguns problemas de validade da medida. Ele mostra que dois sistemas com NEP semelhantes podem registrar dinâmicas competitivas bastante distintas. Para Golosov (2010), os conceitos de "viabilidade", “importância" ou "realidade" necessitam de medidas distintas e mais complexas para serem representados. Em outros termos, sistemas com NEP próximo podem ser mais competitivos que outros, dependendo de como estão distribuídos os resultados eleitorais (GOLOSOV, 2010). Precisamente, situaçóes em que um partido alcança mais de $50 \%$ dos votos não podem ser comparadas a outras em que isso não ocorre, mesmo que os NEPs sejam numericamente próximos.

Apesar desse alerta, neste trabalho o NEP será mantido como a principal medida representativa da variável dependente. Afinal, pretende-se apenas observar que a magnitude altera significativamente o número de partidos com reais chance de vitória. Para tanto, uma medida que sintetize a distribuição dos votos entre os partidos é fundamental. Além disso, o NEP é a medida mais utilizada em trabalhos com temas próximos ao nosso (NICOLAU e SCHMITT, 1995; GUARNIERI, $2015)^{10}$.

\section{Metodologia e Resultados}

De acordo com a literatura, a Lei de Duverger é traduzida por duas proposiçôes e está apoiada em dois mecanismos específicos: os efeitos mecânico e psicológico. A fórmula e o número de vagas são os componentes eleitorais básicos para o raciocínio. Precisamente, espera-se que o efeito mecânico aumente quando há uma redução no número de vagas. Adicionalmente, o efeito psicológico, quer seja no eleitor, quer seja nos dirigentes partidários, deve reforçar essa tendência, reduzindo o número de candidatos e a fração de votos conferida aos perdedores.

\footnotetext{
${ }^{10} \mathrm{Na}$ verdade, Guarnieri (2015) utiliza o número efetivo de candidatos à governador do estado, o que se aproxima muito do NEP já que o voto na legenda pode ser considerado baixo no Brasil.
} 
Para o Senado brasileiro, essas expectativas podem ser consideradas razoáveis tendo em vista a fórmula e o tipo de voto utilizados. Caso se ignore as demais variáveis, as disputas tenderiam para o bipartidarismo, ou seja, para disputadas entre os dois grandes partidos constitutivos do sistema ${ }^{11}$. No Brasil, o Senado é composto por 81 membros eleitos via princípio majoritário de turno único. Os mandatos têm duração de oito anos. A renovação é feita de quatro em quatro anos, sendo alternada entre um e dois terços da Casa (CODATO et al., 2016). Normalmente, o voto é conferido aos candidatos, embora o eleitor tenha a opção de votar na legenda. $\mathrm{Na}$ prática, isso significa que, em caso de renovaçáa de dois terços, o eleitor pode votar em candidatos de partidos/coligaçôes diferentes ${ }^{12}$. A consequência básica do voto nominal é o aumento virtual das chances de vitória de um candidato quando há o aumento na magnitude (NICOLAU e SCHMITT, 1995).

Dessa forma, nosso objetivo principal é estimar o efeito da magnitude no NEP da eleição para o Senado no Brasil. Nossa hipótese é que a magnitude exerce um efeito positivo e significativo sobre o NEP. Porém, antes de testá-la precisamos apresentar outros detalhes do nosso desenho de pesquisa, como a série temporal, as variáveis de controle e as técnicas que serão utilizadas para análise. O quadro abaixo sumariza a nossa metodologia.

Quadro 1 - Resumo da Metodologia

\begin{tabular}{|c|c|c|}
\hline \multicolumn{2}{|c|}{ Elemento } & Descriçáo \\
\hline \multicolumn{2}{|c|}{ Questão de Pesquisa } & Qual o efeito da magnitude sobre o NEP da eleição para o Senado brasileiro? \\
\hline \multicolumn{2}{|c|}{ Hipótese } & $\begin{array}{l}\text { A magnitude exerce um efeito positivo e significativo sobre o Número Efetivo } \\
\text { de Partidos (NEP). }\end{array}$ \\
\hline \multicolumn{2}{|c|}{ Unidade de Análise } & Eleiçôes de Senadores: 26 Estados + Distrito Federal \\
\hline \multicolumn{2}{|c|}{ Série Temporal } & $1998-2018$ \\
\hline \multirow{2}{*}{ 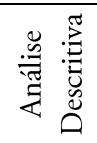 } & Variáveis & $\begin{array}{l}\text { Eleição; Magnitude; NEP; Número de Candidatos; Razão Derrotados; } \\
\text { Votos Válidos; Concentração Presidente; Concentração Governador. }\end{array}$ \\
\hline & Técnicas & Estatística Descritiva. \\
\hline \multirow{2}{*}{ 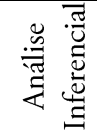 } & Variáveis & $\begin{array}{l}\text { VD = NEP; VI = Magnitude; VC = Número de Candidatos; Candidato/Vaga; } \\
\text { Votos Válidos; Concentração Presidente; Concentração Governador. }\end{array}$ \\
\hline & Técnicas & Modelos de Regressão Linear por Mínimo Quadrados Ordinários (MQO). \\
\hline
\end{tabular}

Fonte: Elaborado pelos autores.

\footnotetext{
${ }^{11}$ Agradecemos à pareceristas anônimos a inclusão da concepção de bipartidarismo para o trabalho.

${ }^{12}$ No caso de renovação de dois terços, cada eleitor tem direito a dois votos, porém ele não pode ser conferido ao mesmo candidato, embora possa ser conferido ao mesmo partido/coligação.
} 
O desenho fica ainda mais claro com os detalhes sobre os procedimentos para cálculo de cada variável, em especial, a dependente e a independente. Quanto ao número efetivo de partidos, utilizaremos a fórmula proposta por Laakso e Taagepera (1979) já discutida anteriormente. Nossa variável independente (Magnitude) corresponde ao número de vagas em disputa, o que equivale a uma ou duas por estado, conforme o nível de renovação da Casa (um ou dois terços). Adicionalmente, a variável Razão Derrotados indica a distância entre o primeiro e o segundo candidato perdedor. A função é sinalizar quais disputas estáo em equilíbrio duvergeriano. As demais variáveis serão consideradas como controle. O número de candidatos tem a função de controlar as estratégias de campanha dos partidos. Os votos válidos sinalizam a importância que os eleitores conferem ao pleito. Por fim, o uso das concentraçóes $(\mathrm{HH})$ de votos para a corrida presidencial e para os governos dos estados tenta controlar o efeito das eleiçóes simultâneas ${ }^{13}$. O quadro abaixo apresenta detalhes das variáveis analisadas neste trabalho.

Quadro 2 - Listas de Variáveis

\begin{tabular}{|c|c|c|c|}
\hline Tipo & Nome & Descriçáo & $\begin{array}{c}\text { Nível de } \\
\text { Mensuraçáo }\end{array}$ \\
\hline Dependente & NEP & $\begin{array}{l}\text { Razão entre } 1,00 \text { e o somatório do quadrado das } \\
\text { proporçóes de votos. }\end{array}$ & Razão/Contínua \\
\hline Independente & Magnitude & Número de vagas em disputa a cada eleiçáo. & Nominal \\
\hline \multirow{5}{*}{ Controles } & $\begin{array}{l}\text { Número de } \\
\text { Candidatos }\end{array}$ & Número de candidatos para o Senado. & Razão/Discreta \\
\hline & $\begin{array}{l}\text { Razáo entre os } \\
\text { Derrotados }\end{array}$ & $\begin{array}{l}\text { Razão entre os percentuais de votos do } 1^{\circ} \text { e do } 2^{\circ} \\
\text { perdedor. }\end{array}$ & Razão/Contínua \\
\hline & Votos Válidos & Percentual de votos válidos para o Senado. & Razão/Contínua \\
\hline & $\begin{array}{l}\text { Concentração } \\
\text { Presidente }\end{array}$ & $\begin{array}{l}\text { Somatório do quadrado do percentual de votos } \\
\text { dos candidatos à presidência na UF. }\end{array}$ & Razão/Contínua \\
\hline & $\begin{array}{l}\text { Concentraçáo } \\
\text { Governador }\end{array}$ & $\begin{array}{l}\text { Somatório do quadrado do percentual de votos } \\
\text { dos candidatos a Governador na UF. }\end{array}$ & Razão/Contínua \\
\hline
\end{tabular}

Fonte: Elaborado pelos autores.

${ }^{13}$ Ambas são calculadas pelo índice de concentração de Herfindahl-Hirschman: $\mathrm{HH}=\sum_{i=1}^{\infty} P_{i}^{2}$ 


\section{Resultados}

No Brasil, não existem muitos estudos que investigam sistematicamente a relação entre os sistemas eleitoral e partidário (LIMA JUNIOR, 1997; GUARNIERI, 2015). Sem dúvidas, Guarnieri (2015) realizou o exemplo mais recente e mais próximo do nosso. O objetivo dele foi testar as proposiçôes do Duverger "no que tange às eleições majoritárias no Brasil” (GUARNIERI, 2015, p. 79). Para tanto, analisou as corridas para as prefeituras e para o governo dos estados. Diferente de nós, Guarnieri (2015) estava particularmente interessado no efeito da realização de dois turnos no número de candidatos. Aqui, nosso foco recai sobre a magnitude. A intenção é estender o argumento do Duverger (1970) testando o efeito da magnitude sobre o número efetivo de partidos para o Senado brasileiro.

Para tanto, nosso ponto de partida é a análise da distribuição da variável dependente. Para não perder tempo, analisa-se o comportamento do NEP considerando as eleições e a magnitude. Aqui o objetivo principal é verificar se pleitos com magnitudes mais altas registram, na média, um maior número de partidos efetivos. A figura abaixo ilustra essa estatística.

Figura 1 - Distribuição do Número Efetivo de Partidos (NEP) por eleição e por magnitude (1998 2018)
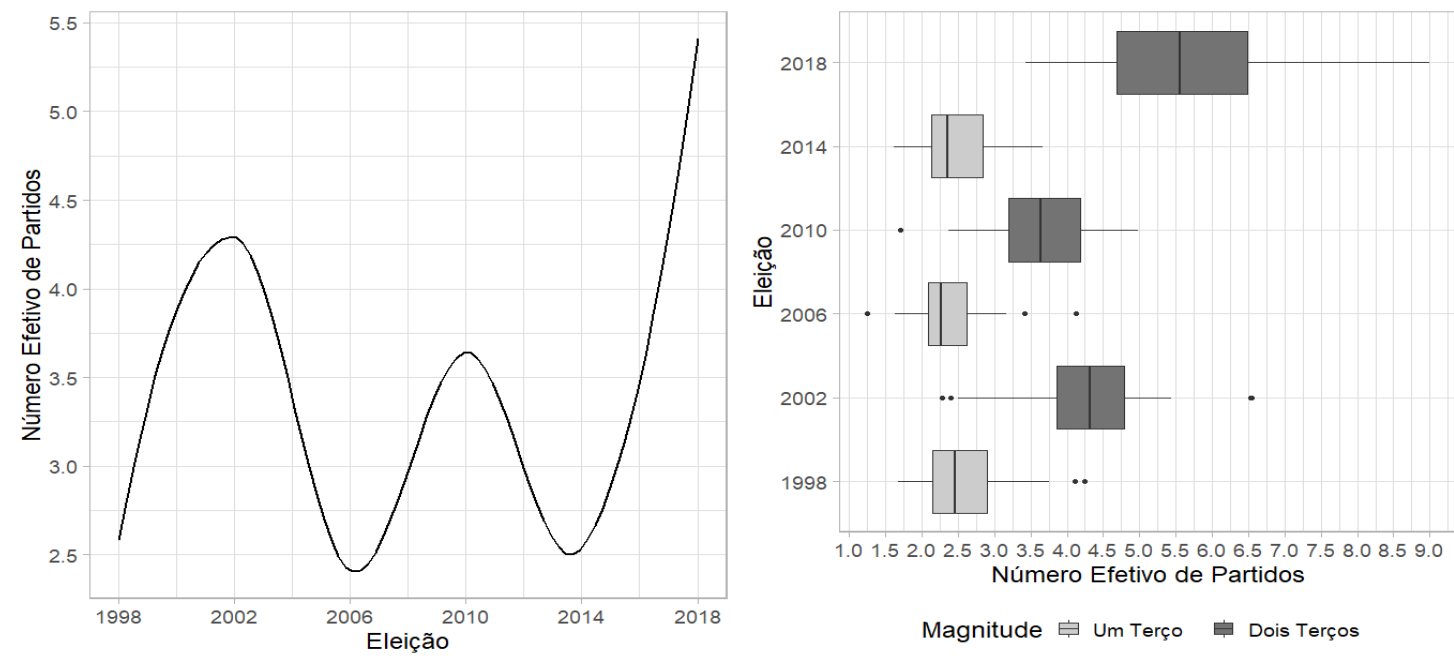

Fonte: Elaboração própria com base em dados do TSE (2018). 
164 | José Alexandre da S. Júnior, Willber Nascimento, Albany F. Lima e Widyane da S. Omena

Claramente, os pleitos em que há apenas uma vaga em disputa por estado (um terço) registram estatísticas menores. Tanto a média quanto a mediana das distribuições de eleições com essa magnitude são menores em toda a série. Mais precisamente, a menor média foi registrada $2006(\bar{X}=2.41)$ e a maior em 2018 $(\bar{X}=5.41)^{14}$. Para completar essa análise, a figura abaixo traz um histograma e um gráfico de caixa do NEP agrupado apenas pela magnitude.

Figura 2 - Distribuição do Número Efetivo de Partidos (NEP) por magnitude da eleição (1998-2018)
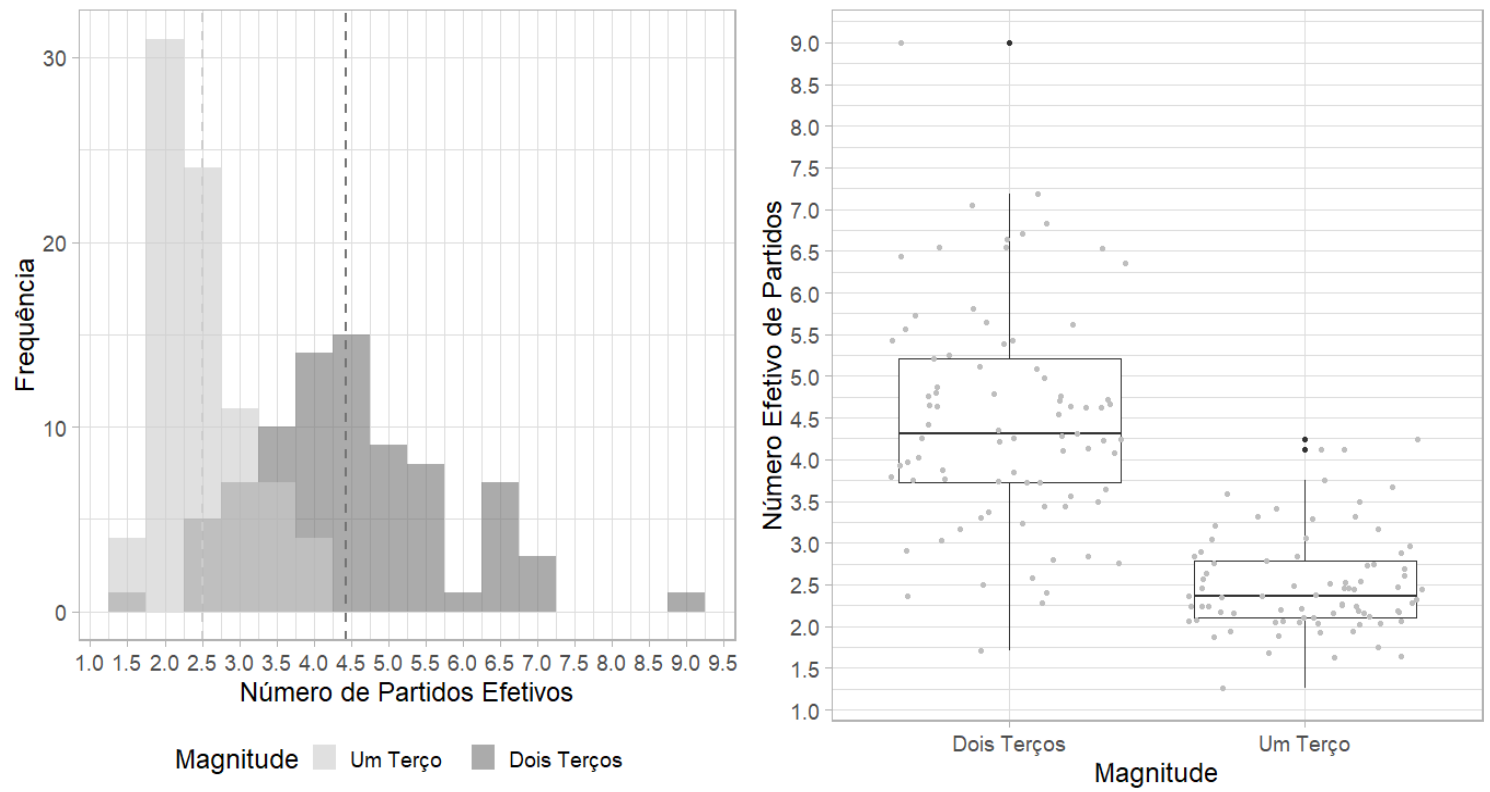

Fonte: Elaboração própria com base em dados do TSE (2018).

No histograma (gráfico à esquerda) fica claro que a zona de interseção entre as duas distribuições é pequena (cinza intermediário). Mais que isso, as linhas tracejadas que representam as médias das distribuiçóes estão plotadas a aproximadamente dois pontos de distância uma da outra. Enquanto a média do NEP para eleiçóes de um terço é $\bar{X}=2.51$, a mesma estatística para as eleições de dois terços é $\bar{X}=4.49$. Portanto, o resultado mostra que as eleiçóes de um terço tendem a configurar disputas com a presença de dois partidos com maior peso na distribuição de votos. Entretanto, precisamos confirmar se esses partidos são os mesmos em todo território

\footnotetext{
${ }^{14}$ Registra-se a presença de outliers ou pontos influentes em quatro das seis eleiçóes. Chama a atenção ainda o fato de a variação ser sempre menor nos anos em que apenas uma vaga está em disputa.
} 
para aproximar essas disputas de um bipartidarismo ${ }^{15}$. A figura mostra ainda que as observaçóes são mais dispersas em magnitude de dois terços. O próximo passo é testar a diferença entre as médias do NEP considerando o número de vagas em disputa. A figura abaixo ilustra esse teste.

Figura 3 - Diferença entre as médias de NEP por ano e por magnitude (1998 - 2018)

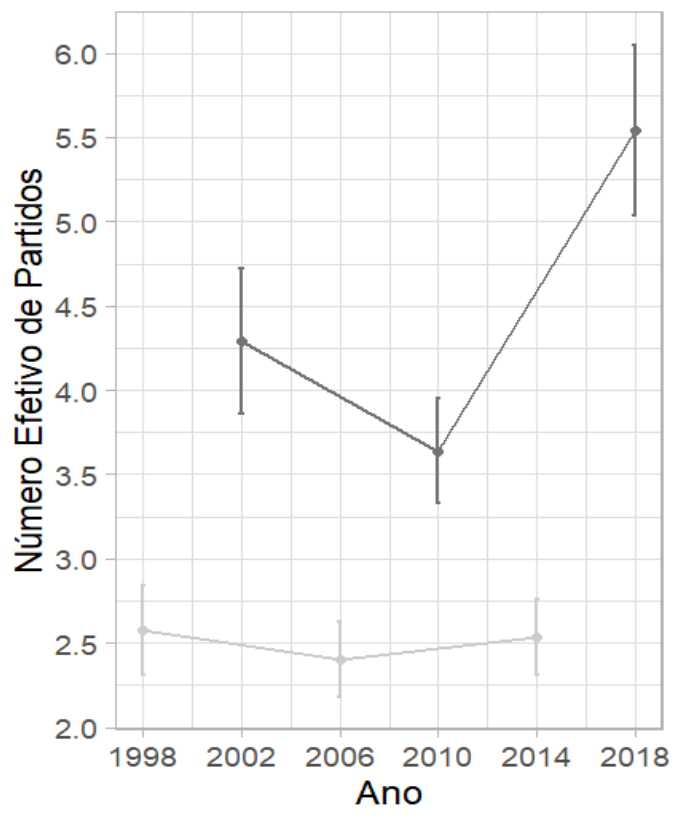

Magnitude $\rightarrow$ Dois Terços $\rightarrow$ Um Terç

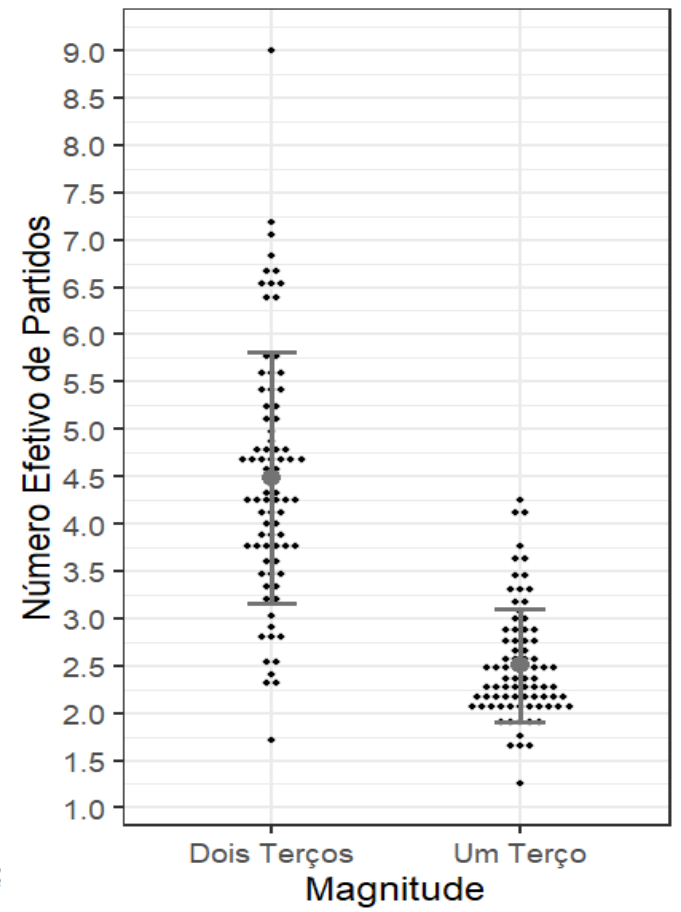

Fonte: Elaboração própria com base em dados do TSE (2018).

$\mathrm{F}=27.947 \mathrm{p}<0.000 \mathrm{~T}=12.289 \mathrm{p}<0.000^{16}$

A diferença entre as médias é estatisticamente significativa. Todos os pleitos de magnitude de dois terços têm médias significativamente maiores. Tanto no gráfico de barra de erro por ano quanto no por magnitude não há zonas de interseção entre as barras. $\mathrm{Na}$ prática, isso significa que não há convergência entre os intervalos de confiança das médias dos dois grupos; logo, a probabilidade de as médias serem iguais é baixa $(\mathrm{T}=12.289 \mathrm{p}<0.000)$.

\footnotetext{
${ }^{15}$ Agradecemos à pareceristas anônimos a sugestão de inclusão desse comentário.

16 Teste de diferença entre médias considerando os dois tipos de magnitude. $\mathrm{O}$ teste foi realizado com a retirada de pontos influentes/outlier e o resultado manteve-se substantivamente igual.
} 
Como esperado, há uma relação positiva entre a magnitude e o número efetivo de partidos. Isso pode ser gerado por dois fatores: 1) o eleitor decide distribuir seus votos em candidatos de partidos diferentes e 2) os partidos decidem lançar apenas um candidato quando poderiam apresentar dois. $\mathrm{Na}$ segunda situação, o eleitor seria forçado a votar em partidos diferentes no mesmo pleito. ${ }^{17} \mathrm{Na}$ tentativa de saber o que de fato acontece, examinamos o gráfico abaixo (Figura 4). Ele apresenta o percentual médio de partidos que lançam dois candidatos por unidade da federação em pleitos de magnitude de dois terços.

Figura 4 - Percentual de unidades federativas e média do percentual de partidos com dois candidatos

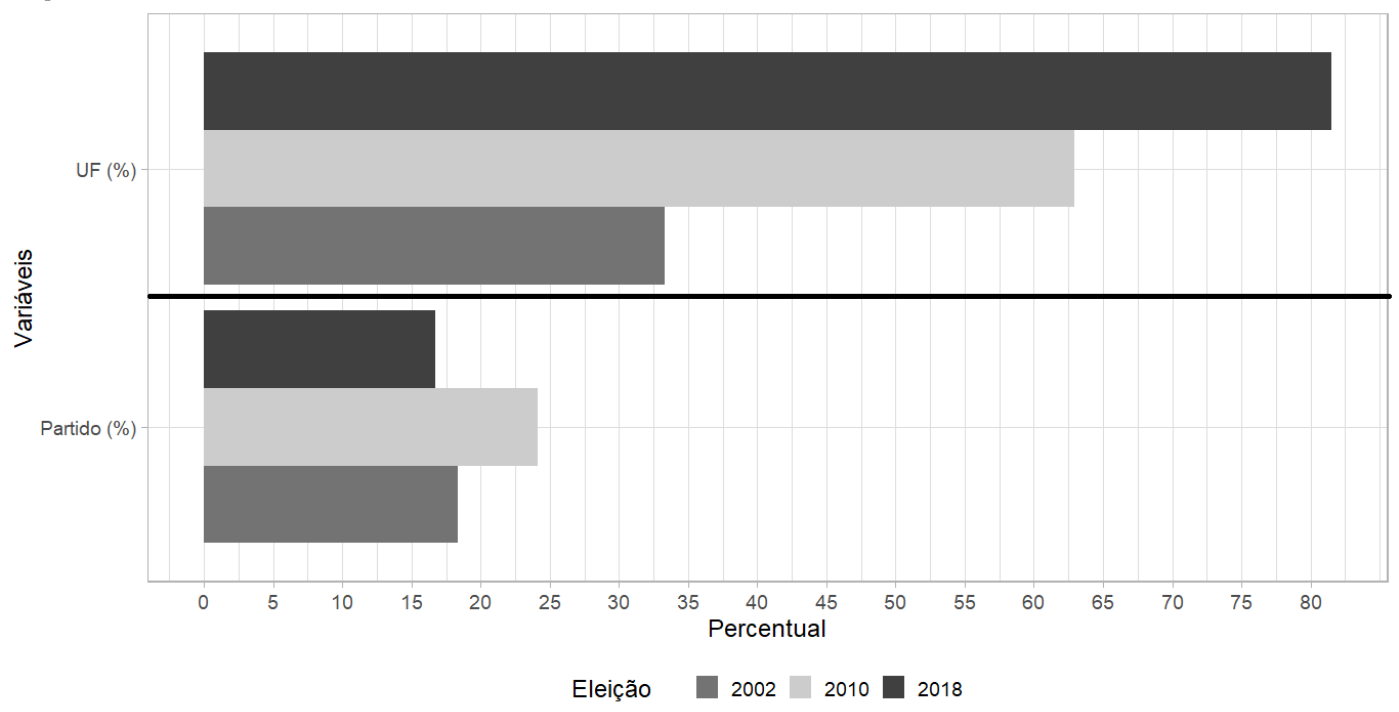

Fonte: Elaboração própria com base em dados do TSE (2018).

Em todos os pleitos há unidades da federaçáo em que nenhum partido lançou dois candidatos. O menor nível desse percentual foi registrado em 2002 (33.33\%). Além disso, a média do percentual de partidos que lançam dois candidatos não ultrapassa os $25 \%$. Em outros termos, em todos os pleitos, menos de um terço dos partidos lançaram dois candidatos em qualquer unidade da federação. Portanto, em vários estados os eleitores não tiveram outra opção a não ser votar em partidos distintos para a eleição dos seus senadores. Mesmo no cenário oposto, não costumam ser muitos os partidos que oferecem essa oportunidade. Por lógica, o número efetivo de partidos tende a crescer nesse cenário.

\footnotetext{
${ }^{17}$ Vale lembrar que a regra não permite o que eleitor direcione seus dois votos ao mesmo candidato.
} 
Os resultados apontam para uma relação forte entre a magnitude e o número efetivo de partidos. Parte dessa relaçáo parece se dever ao número de candidatos que os partidos decidem lançar. Os gráficos abaixo ajudam a analisar a relação entre o número de candidatos e o número efetivo de partidos.

Figura 5 - Número de candidatos por eleição e número efetivo de partidos (1998 - 2018)

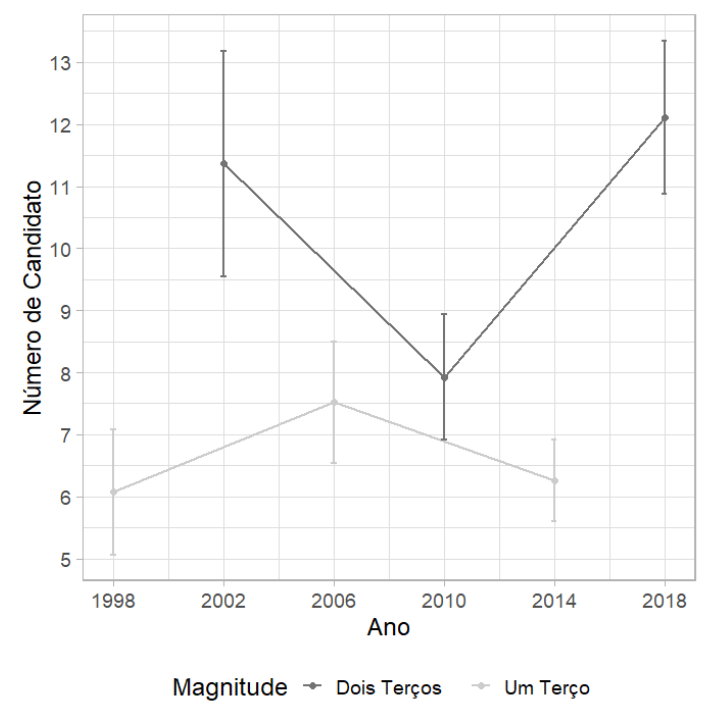

$\mathrm{F}=12.026 \mathrm{p}<0.000 \mathrm{~T}=7.575 \mathrm{p}<0.000^{18}$

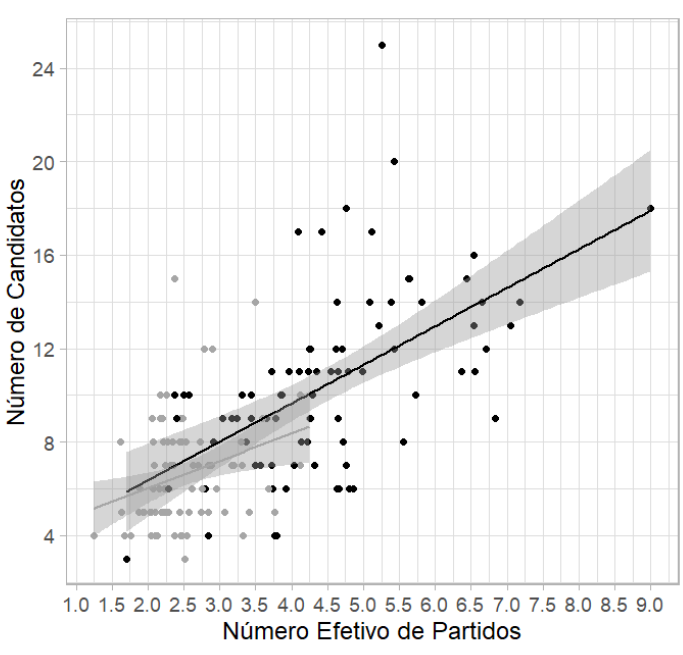

Magnitude $\rightarrow$ Dois Terços $*$ Um Terço $r=0.30 p<0.05 r=0.55 p<0.05$

Fonte: Elaboração própria com base em dados do TSE (2018).

A média de candidatos é maior nos pleitos com magnitude de dois terços. A diferença entre as médias é significativa considerando grupos formados a partir das magnitudes $(\mathrm{T}=7.575 ; \mathrm{p}<0.000)$. Embora esse resultado pareça óbvio, vale lembrar que poucos partidos lançam dois candidatos nos pleitos de maior magnitude. Portanto, parece que um número maior de partidos acaba lançado candidatos nos pleitos de dois terços. A correlação entre o número de candidatos e o número efetivo de partidos é positiva e significativa independentemente da magnitude. Porém, ela é maior dentre os pleitos com magnitude mais alta $(\mathrm{r}=0.55 ; \mathrm{p}<0.05)$. Na prática, isso significa que parte da variação do número efetivo de partidos pode ser explicada pela lógica de lançamento de candidaturas.

18 Teste de diferença entre médias considerando os dois tipos de magnitude. O mesmo teste foi realizado com a retirada de pontos influentes/outlier, e o resultado manteve-se substantivamente igual. 
As estratégias partidárias são um elemento caro para análise da aplicação da Lei de Duverger. As eleições sucessivas ajustam o sistema para o equilíbrio baseado na diferença entre os perdedores. De acordo com Cox (1997), o sistema está em equilíbrio quando a diferença entre o primeiro e o segundo perdedor são significativas. Nesse cenário, aumentar o número de candidaturas seria irracional (COX, 1997). Os gráficos abaixo ilustram o equilíbrio das disputas para o Senado no Brasil.

Figura 6 - Razão entre o percentual de votos dos candidatos derrotados (1998 - 2018)
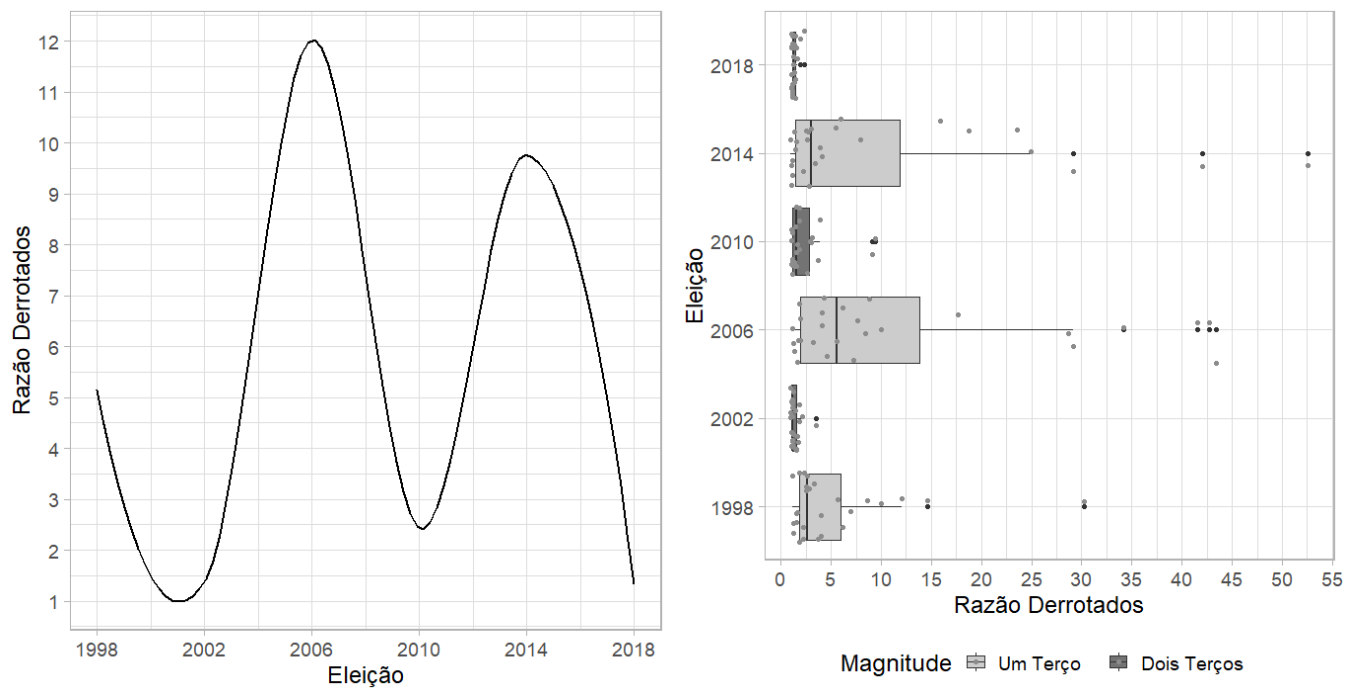

Fonte: Elaboração própria com base em dados do TSE (2018).

Claramente, a média da razão é mais baixa nos pleitos em que há duas vagas em disputa. A dispersão entre os casos também é menor com essa magnitude. $\mathrm{Na}$ prática, isso significa que pleitos de magnitude maior tendem a gerar menos equilíbrio. Em outros termos, a diferença entre o primeiro perdedor e o segundo é mais apertada quanto há duas vagas por estado para serem preenchidas. Em resumo, nesse tipo de magnitude há um maior número de partidos efetivos, mais candidatos e menos equilíbrio.

Antes de seguir para uma análise mais rigorosa sobre o efeito da magnitude, iremos nos deter na investigação do nível de competitividade dos partidos. Segundo Duverger (1970), disputas decididas por maioria simples de turno único tendem a ser bipartidárias. Porém, tanto Sartori (1968) quanto Shugart e Carey (1992) colocam algumas condiçôes para extensão dessa sentença. $\mathrm{O}$ caso brasileiro representa bem 
algumas dessas condições. Aqui existem eleições simultâneas com base em fórmulas distintas. Portanto, dificilmente tenderíamos para o bipartidarismo, mesmo na disputa para Senado. Esse quadro pode ser visto a partir dos gráficos a seguir. Neles aparecem apenas os partidos que figuraram no grupo dos principais competidores, ou seja, dentre os que estão na pior das hipóteses como o primeiro derrotado.

Figura 7 - Frequência dos partidos no grupo de principais competidores $\left(1998\right.$ - 2002) $(\%)^{19}$

1998

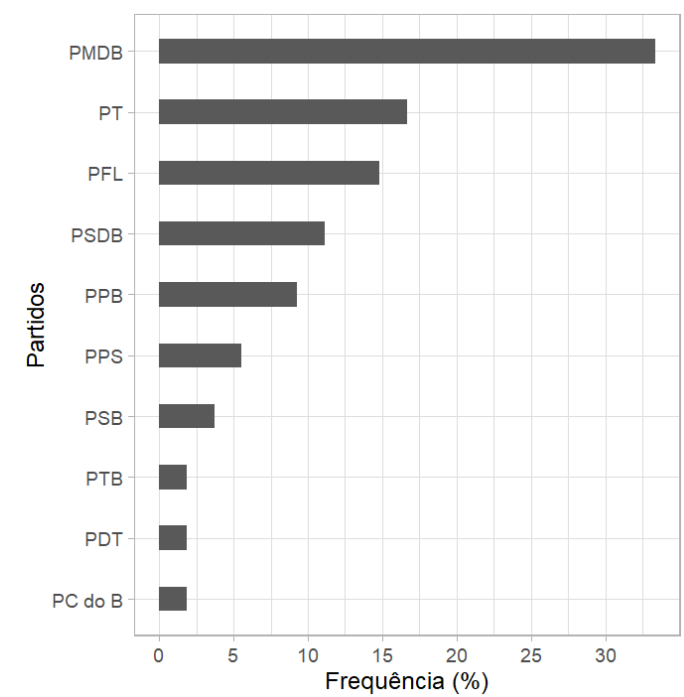

2002

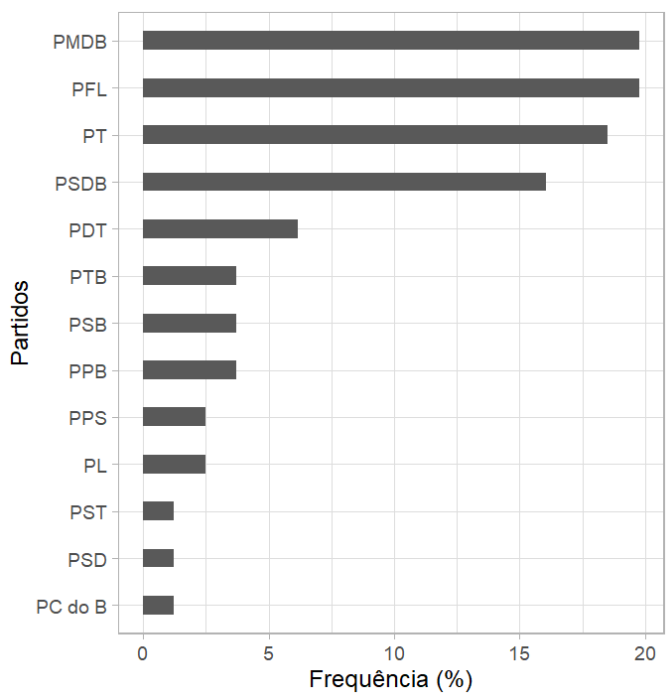

Fonte: Elaboração própria com base em dados do TSE (2018).

19 O cálculo é feito com base no total de partidos contabilizados caso os sistemas estivessem em equilíbrio, para $M=1$, são dois partidos por $U F$ total $=54$, para $M=2$, são três partidos por UF total $=81$. 
170 | José Alexandre da S. Júnior, Willber Nascimento, Albany F. Lima e Widyane da S. Omena

Figura 8 - Frequência dos partidos no grupo de principais competidores (2006 - 2010) (\%)
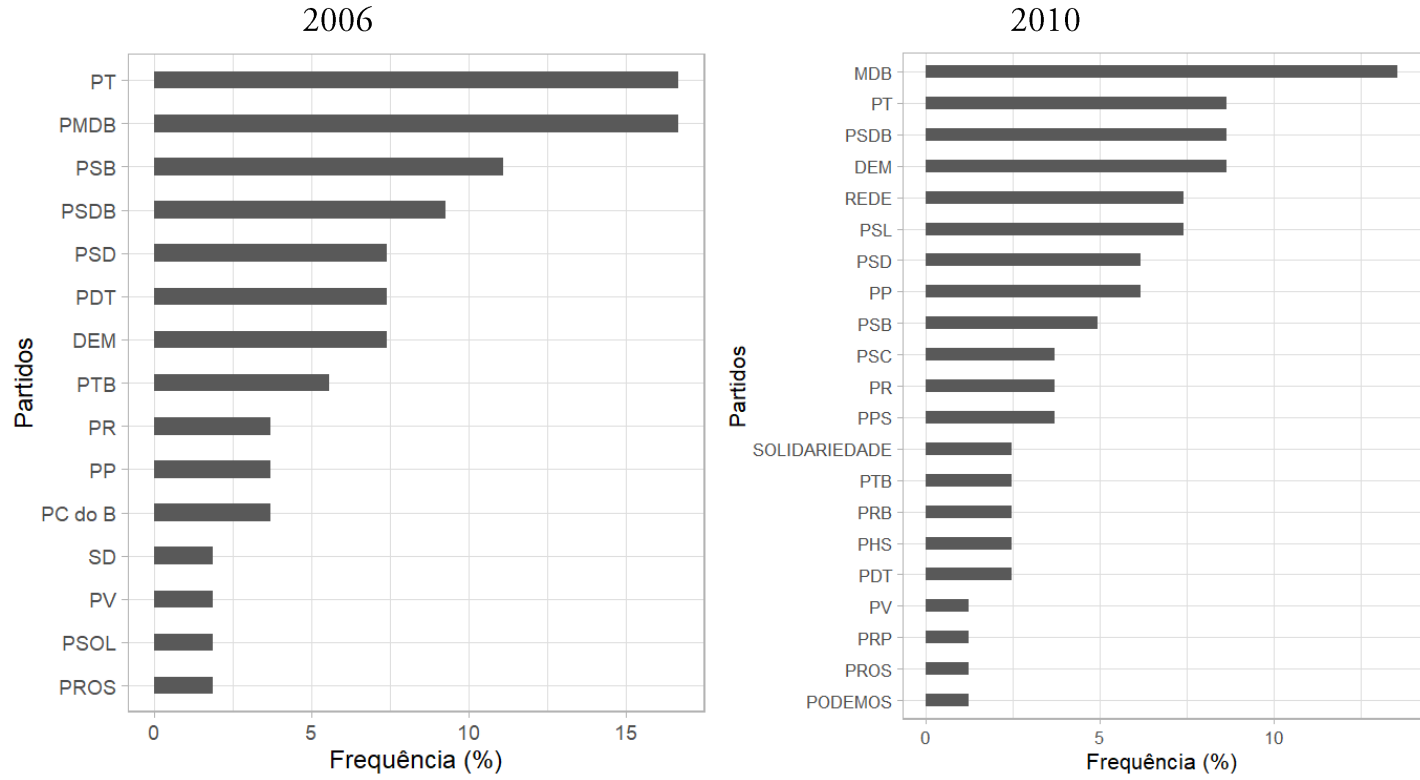

Fonte: Elaboração própria com base em dados do TSE (2018). 
Figura 9 - Frequência dos partidos no grupo de principais competidores (2014 - 2018) (\%)

2014

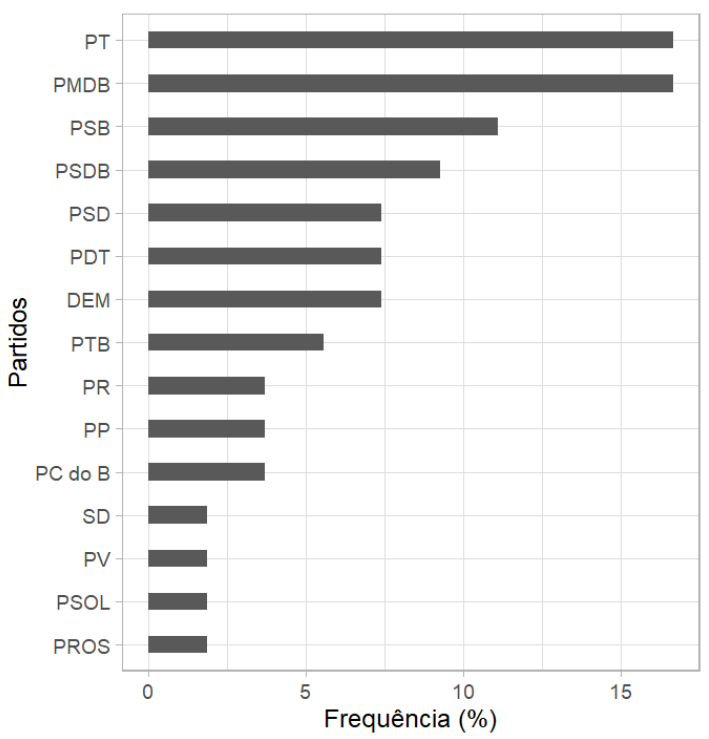

2018

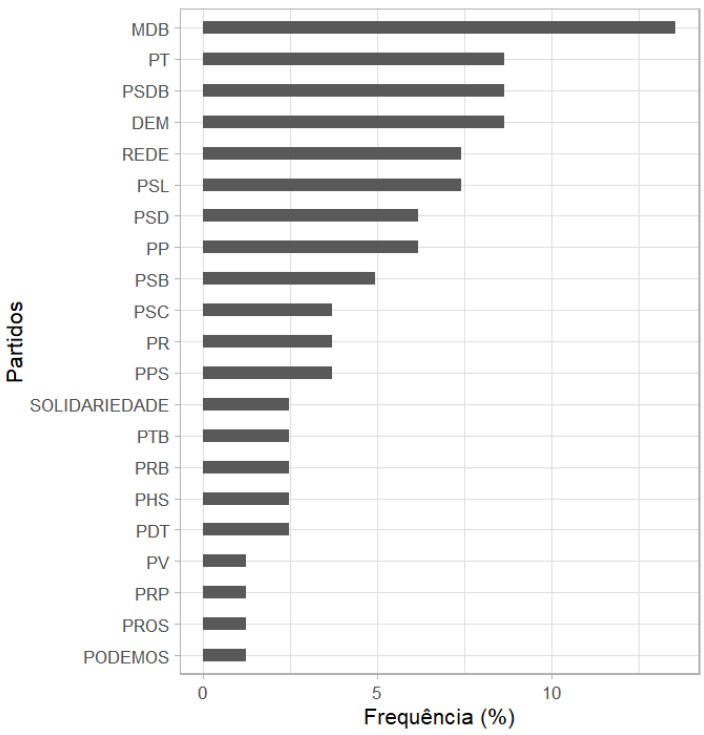

Fonte: Elaboração própria com base em dados do TSE (2018).

Figura 10 - Número e Percentual de Participação de Partidos no Grupo de Principais Competidores (1998-2018)
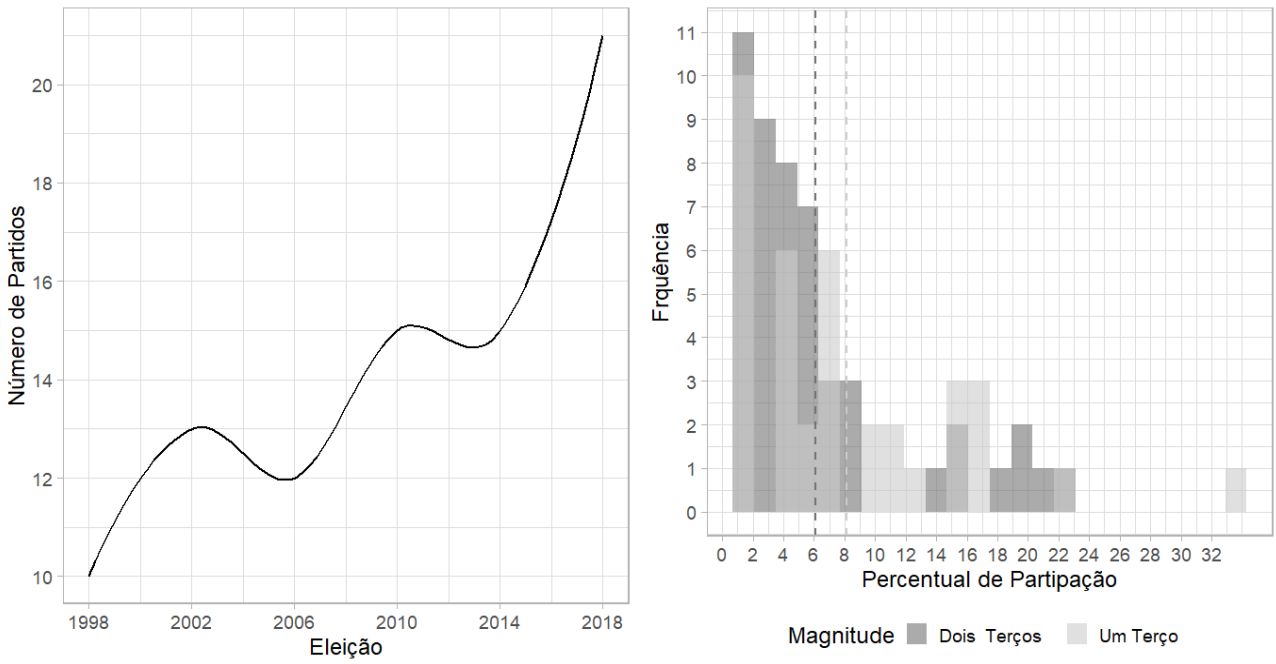

Fonte: Elaboração própria com base em dados do TSE (2018). 
Os seis primeiros gráficos referem-se aos seis pleitos analisados aqui na ordem crescente da esquerda para direita. Em todos, PMDB (MDB), PT e PSDB aparecem dentre os cinco partidos mais competitivos. Em 1998, por exemplo, o PMDB aparece como partido competitivo em 18 estados. A melhor marca do PT é registrada em 2010, quando o partido figura como competitivo em 17 estados. Por fim, a melhor performance do PSDB foi registrada em 2002, quando o partido aparece no grupo dos competitivos em 13 estados da federação. $\mathrm{O}$ número de partidos no grupo dos competitivos cresce ao longo da série, em 1998 faziam parte apenas 10 partidos, contra 21 partidos na última eleição (2018). A magnitude parece fazer pouca diferença nesse número. De acordo como o histograma, há uma grande zona de interseção entre os percentuais das duas magnitudes. Mais que isso, as médias dos grupos (linhas pontilhadas no histograma) estão próximas, divergindo em aproximadamente dois pontos $(\bar{X}=6.12$ e $\bar{X}=8.11$, respectivamente). No conjunto, esses resultados mostram que é difícil falar em bipartidarismo nas eleições para o Senado - ao menos se esse conceito for definido como um sistema com a presença de apenas duas legendas principais ${ }^{20}$. $\mathrm{Na}$ média, os partidos aparecem como competitivos em menos de $10 \%$ das disputas no território nacional.

Segundo Sartori (1968), o nível de nacionalização dos partidos é uma variável importante para ponderar as proposiçóes de Duverger (1970). Quanto mais localizada a presença dos partidos nos estados, menor a chance de prevalecer o bipartidarismo. Além disso, Shugart e Carey (1992) acreditam que a simultaneidade entre os pleitos tem efeito sobre o número de partidos. Para observar essa influência, decidimos observar a correlação entre a concentração de votos na corrida para presidência e para governo nos estados e o número efetivo de partidos para o Senado. Esperamos encontrar correlaçôes negativas e significativas entre as variáveis. Em outros termos, acreditamos que a competição mais acirrada (concentração baixa) esteja correlaciona com o maior número de partidos efetivos para o Senado.

\footnotetext{
${ }^{20}$ Agradecemos à pareceristas anônimos a sugestão de definir o conceito de bipartidarismo em algumas passagens do trabalho.
} 
Figura 11 - Concentração de votos (Presidente e Governador) e NEP do Senado (1998 - 2018) (\%)
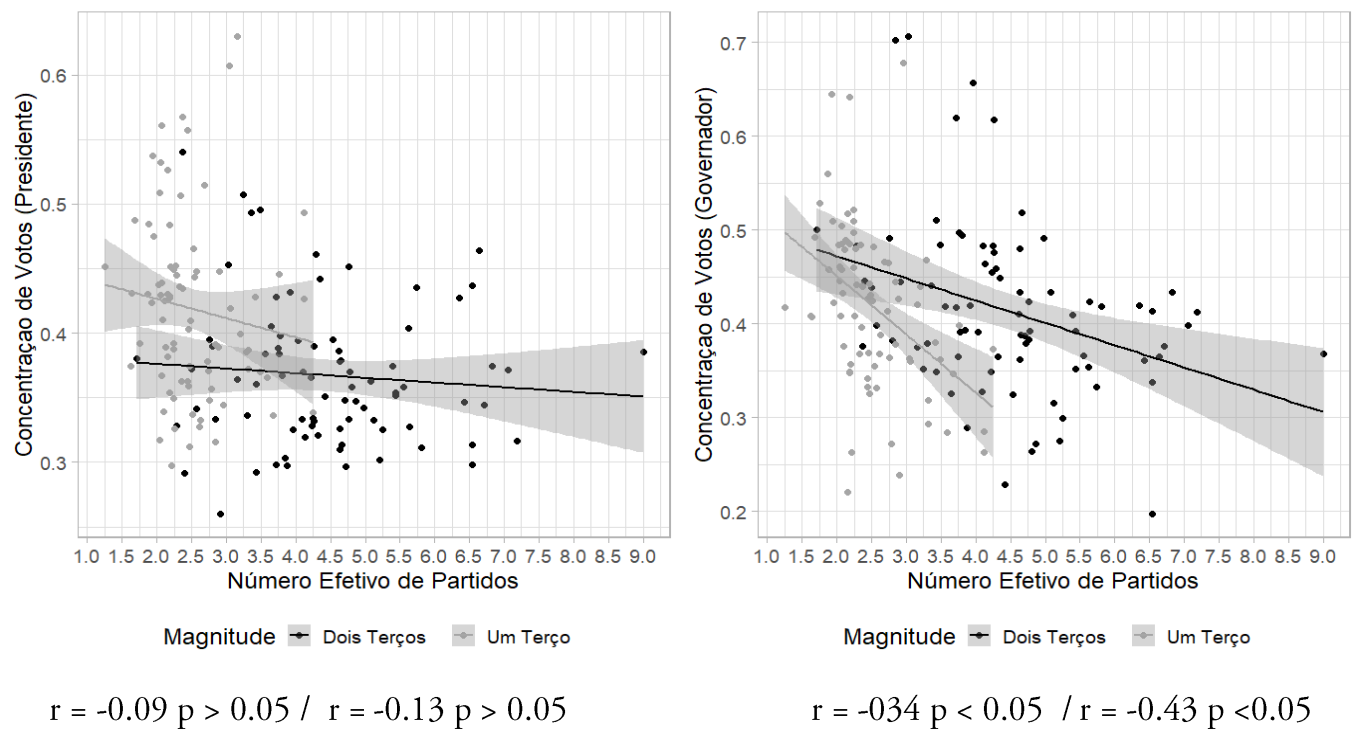

Fonte: Elaboração própria com base em dados do TSE (2018).

Todas as correlações são negativas como o esperado. A magnitude dos coeficientes é sempre maior dentre os pleitos de um terço. No entanto, apenas as correlações entre o NEP e a concentração de votos da corrida para os governos dos estados são significativas $(r=-0.34 \mathrm{p}<0.05 ; \mathrm{r}=-043 \mathrm{p}<0.05)$. Ao que parece, quando a disputa para o governo é mais acirrada a distribuição de votos entre os partidos que disputam o Senado se torna mais dispersa. O que confirma em alguma medida a expectativa da literatura.

Em síntese, a análise descritiva trouxe cinco achados importantes: 1) o NEP é maior em pleitos de magnitude correspondente a dois terços; 2) A maioria dos partidos lança apenas um candidato em eleiçóes com duas vagas em disputa; 3) O equilíbrio duvergeriano é mais frequente em eleições de um terço; 4) Em média, os partidos competitivos estão presentes em menos de $10 \%$ das disputas no território nacional; e 5) a concentração de votos da disputa pelos governos dos estados está negativamente correlacionada com número de partidos efetivos do Senado. 
174 | José Alexandre da S. Júnior, Willber Nascimento, Albany F. Lima e Widyane da S. Omena

\section{Métodos}

Munidos dos achados da análise descritiva, partimos para estimar o efeito da magnitude sobre o número de partidos efetivos. Primeiro, fizemos a transformação das variáveis cuja distribuição está afastada da normalidade: 1) NEP; 2) N. Candidatos; 3) Percentual de Votos Válidos; Razão entre os primeiros Derrotados ${ }^{21}$. Precisamente, calculamos os logaritmos naturais dessas variáveis e iremos trabalhar com eles. A figura abaixo apresenta o coeficiente da variável independente e dos controles sobre o NEP.

Figura 12 - Modelo de regressão linear de mínimos quadrados ordinários

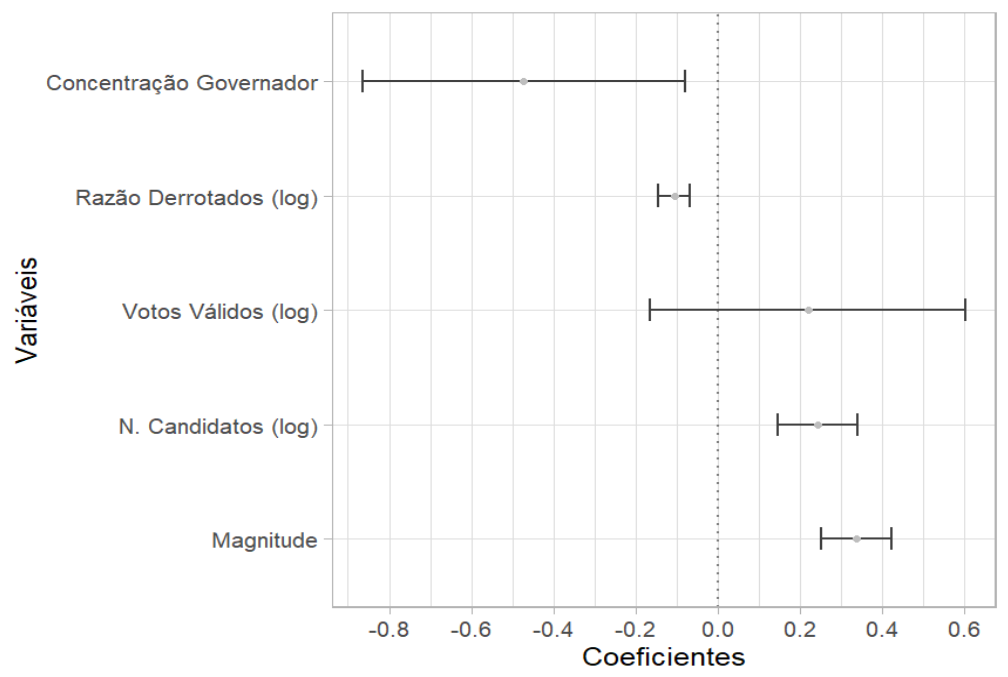

Fonte: Elaboração própria com base em dados do TSE (2018).

$\mathrm{R}^{2}$ Ajustado $=0.714 \quad \mathrm{~F}=80.58 \quad \mathrm{p}<0.00$

Com exceção do percentual dos votos válidos, todas as variáveis apresentam coeficientes significativos estatisticamente ${ }^{22}$. Enquanto a razão entre derrotados e a concentração de votos das disputas para os governos estaduais tem efeito negativo, o número de candidatos e a magnitude afetam positivamente o NEP da eleição para o Senado. Precisamente, cada ponto a mais na concentração reduz o NEP em pouco mais de $60 \%$. Já o aumento de um ponto percentual na razão entre os derrotados deve reduzir o NEP em aproximadamente $0,20 \%$. Cada ponto percentual a mais no

\footnotetext{
${ }^{21}$ Todas as transformações foram feitas com base na análise do histograma de todas as variáveis.

${ }^{22}$ Graficamente basta o intervalo de confiança não passar pelo zero, mas detalhes sobre o modelo podem ser consultados nos anexos.
} 
número de candidatos aumenta em aproximadamente $0,25 \%$ o NEP. Por fim, a elevaçáo da magnitude aumenta em pouco mais de 30\% o NEP. Em outros termos, os pleitos de dois terços devem aumentar em cerca de 30\% o NEP da eleição para o Senado, apesar dos controles incluídos no modelo e, principalmente, da manutenção da fórmula eleitora ${ }^{23}$.

\section{Considerações finais}

Estimar o efeito do sistema eleitoral sobre o partidário não é comum no Brasil (LIMA JUNIOR, 1997; GUARNIERI, 2015). Esse trabalho tenta avançar nessa direção investigando a aplicação da Lei de Duverger nas eleições para o Senado brasileiro. O propósito foi investigar o efeito da magnitude sobre o NEP dessas eleiçôes. Nossa hipótese é que a magnitude exerce um efeito positivo e significativo sobre o NEP.

Como visto, apesar da fórmula ser sempre de maioria simples de turno único, o NEP varia por eleição, por estado e, principalmente, pela magnitude dos pleitos. Este estudo mostra que parte dessa variação pode se dever às estratégias partidárias. Entretanto, também parece razoável o fato de os eleitores deliberadamente dispersarem seu voto entre partidos distintos. Juntos, esses dois fatores resultam num NEP médio que varia entre 2.41 e 5.41. Mais que isso, todas as eleições registraram no mínimo dez partidos no grupo dos competitivo. E mesmo os partidos mais frequentes nesse grupo estão longe de alcançar todas as disputas no território nacional.

De certa forma, isso mostra o localismo do sistema partidário e, principalmente, o predomínio de um sistema multipartidário. Além disso, o efeito da realização de eleições simultâneas parece claro no Brasil. De acordo com os resultados, as disputas para os governos estaduais têm um efeito significativo sobre o NEP.

Parte da variação do NEP deve-se à magnitude alternada dos pleitos. $\mathrm{Na}$ média, o NEP é menor em eleições de um terço da Casa. Além disso, a média da razão entre o primeiro e o segundo candidato derrotado é maior nos pleitos de um terço. Em outros termos, a elevação da magnitude coloca mais obstáculo ao alcance do equilíbrio. No geral, a primeira proposição de Duverger, de que disputas por maioria simples de turno único tendem ao bipartidarismo, deve ter uma aplicação

\footnotetext{
${ }^{23}$ A mesma estimação foi feita utilizando o modelo de MQO para dados de painel, os resultados são muito semelhantes ao de dados agrupados.
} 
condicionada no Brasil. As ponderações que a literatura fez no percurso de acúmulo de conhecimento sobre a lei aplicam-se bem ao caso das eleiçóes para o Senado brasileiro. Certamente importam para os resultados o nível de nacionalização dos partidos, a ocorrência de eleições simultâneas e as estratégias definidas pelos dirigentes partidários. O resultado é que o bipartidarismo não surge, apesar da fórmula de disputa.

José Alexandre da Silva Júnior é Doutor em Ciência Política pela Universidade Federal de Pernambuco (UFPE). É Professor do Instituto de Ciências Sociais (ICS), da Universidade Federal de Alagoas. E-mail: jasjunior2007@yahoo.com.br.

Willber Nascimento é Doutorando do Programa de PósGraduação em Ciência Política da UFPE (PPGCP/UFPE). E-mail: nascimentowillber@gmail.com.

Albany Ferreira Lima é Doutorando do Programa de PósGraduação em Ciência Política da UFMG (PPGCP/UFMG). E-mail: albanyinformatica@gmail.com.

Widyane da Silva Omena é Graduada em Ciências Sociais pelo Instituto de Ciências Sociais (ICS/UFAL). E-mail: widyaneso@hotmail.com.

\section{Referências}

CARAMANI, Danieli. The End of Silent Elections. The Birth of Electoral Competition 1832-1915. Party Politics, v. 9, n. 4, p. 411-443, 2003.

CODATO, Adriano et al. Regime político e recrutamento parlamentar: um retrato coletivo dos senadores brasileiros antes e depois da ditadura. Rev. Sociol. Polit., v. 24, n. 60, p. 47-68, 2016.

COX, Gary W. Making votes count: strategic coordination in the world's electoral systems. Cambridge: Cambridge University Press, 1997.

DOWNS, Anthony. Uma teoria econômica da democracia. São Paulo: Edusp, 1999.

DUVERGER, Maurice. Duverger's Law: Forty years later. In: GROFMAN, Bernard; LIJPHART, Arend. Electoral Laws and their Political Consequences. New York: Agathon Press, 2003. p. 69-84.

DUVERGER, Maurice. Os Partidos Políticos. São Paulo: Zahar, 1970. 
GOLOSOV, Grigorii V. The Effective Number of Parties: A New Approach. Party Politics, v. 16, n. 2, p. 171-192, 2010.

GRUMM, John. Theories of electoral systems. Midwest Journal of Political Science, v. 2, n. 4, p. $357-$ 376, 1958.

GUARNIERI, Fernando H. E. Voto estratégico e coordenação eleitoral: testando a Lei de Duverger no Brasil. Revista Brasileira de Ciências Sociais, v. 30, n. 89, p. 77-92, 2015.

LAAKSO, Markku; TAAGEPERA, Rein. Effective Number of Parties: A Measure with Application to West Europe. Comparative Political Studies, v. 12, n. 1, p. 3-27, 1979.

LIJPHART, Arend. Electoral Systems and Party Systems: A Study of Twenty-seven Democracies 1945-1990. Oxford: Oxford University Press, 1994.

LIJPHART, Arend. Modelos de Democracia: Desempenho e Padrões de Governo em 36 Países. Rio de Janeiro: Civilização Brasileira, 2003.

LIMA JUNIOR, Olavo B. (Org.). O Sistema Partidário Brasileiro. Rio de Janeiro: Editora FGV, 1997.

LIPSET, Seymour M.; ROKKAN, Stein. Cleavage Structures, Party Systems, and Voter Alignments: An Introduction. In: LIPSET, Seymour M.; ROKKAN, Stein (Orgs.). Party Systems and Voter Alignments: Cross-National Perspectives. New York: Free Press, 1967. p. 1-64.

MAIR, Peter. Party System Change. In: KATZ, Richard; CROTTY, William. (Orgs.). Handbook of Party Politics. London: Sage Publications, 2006. p. 63-73.

MELO, Carlos Ranulfo; CAMARA, Rafael. Estrutura da competição pela Presidência e consolidação do sistema partidário no Brasil. Dados, v. 55, n. 1, p. 71-117, 2012.

MOLINAR, Juan. Counting the Number of Parties: An Alternative Index. American Political Science Review, v. 85, n. 4, p. 1383-1391, 1991.

NICOLAU, Jairo M. Sistemas eleitorais. 6. ed. Rio de Janeiro: FGV, 2012.

NICOLAU, Jairo M.; SCHMITT, Rogério. Sistema eleitoral e sistema partidário. Lua Nova, n. 36, p. 129-147, 1995.

RIKER, William H. Duverger's Law Revisited. In: GROFMAN, Bernard; LIJPHART, Arend. Electoral Laws and Their Political Consequences. New York: Agathon Press, 2003. p. 19-42.

RIKER, William H. The Two-Party System and Duverger's Law: An Essay on the History of Political Science. The American Political Science Review, v. 76, n. 4, p. 753-766, 1982.

ROKKAN, Stein. Citizens, Elections, Parties. New York: Mackaym, 1970.

SARTORI, Giovanni. Comparative Constitutional Engineering. New York: New York University Press, 1994.

SARTORI, Giovanni. The Influence of Electoral Systems: Faulty Laws or Faulty Method? In: GROFMAN, Bernard; LIJPHART, Arend. (Orgs.). Electoral Laws and Their Political Consequences. New York: Agathon Press, 1985. p. 43-68.

SARTORI, Giovanni. Political Development and Political Engineering. In: MONTGOMERY, John; HIRSCHMAN, Albert. (Orgs.). Public Policy. Cambridge: Cambridge University Press, 1968. p. 261-298.

SHUGART, Matthew.; CAREY, John. Presidents and Assemblies: Constitutional Design and Electoral Dynamics. Cambridge: Cambridge University Press, 1992. 
178 | José Alexandre da S. Júnior, Willber Nascimento, Albany F. Lima e Widyane da S. Omena

SILVA, Glauco Peres da. Uma avaliação empírica da competição eleitoral para a Câmara Federal no Brasil. Opinião Pública, v. 19, n. 2, p. 403-429, 2013.

TAAGEPERA, Rein; SHUGART, Matthew. Seats and votes: The effects and determinants of electoral systems. New Haven: Yale University Press, 1989.

TRIBUNAL SUPERIOR ELEITORAL (TSE). Repositório de dados eleitorais. 2018. Disponível em: $<$ http://www.tse.jus.br/eleicoes/estatisticas/repositorio-de-dados-eleitorais-1/repositorio-de-dadoseleitorais>. Acesso em: 07 ago. 2020.

TUFTE, Edward. The relation between seats and votes in two-party systems. American Political Science Review, v. 67, n. 2, p. 540-554, 1973. 


\section{Anexos}

\begin{tabular}{|l|l|l|l|l|}
\hline Min & TQ & Median & $3 \mathrm{Q}$ & Max \\
\hline-0.65917 & -0.08981 & 0.01156 & 0.11480 & 0.46189 \\
\hline
\end{tabular}

Tabela 2 - Coeficientes

\begin{tabular}{|l|l|l|l|l|l|}
\hline & Estimate & Std. & Error & t value & $\operatorname{Pr}(>|\mathrm{t}|)$ \\
\hline (Intercept) & -0.49203 & 0.89021 & -0.553 & 0.581 & \\
\hline Maguinitude & 0.33725 & 0.04389 & 7.685 & $1.68 \mathrm{e}-12$ & $* * *$ \\
\hline PercVotlog & 0.21948 & 0.19428 & 1.130 & 0.260 & \\
\hline Ncandlog & 0.24293 & 0.04944 & 4.913 & $2.27 \mathrm{e}-06$ & $* * *$ \\
\hline ConcGov & -0.47216 & 0.19919 & -2.370 & 0.019 & $*$ \\
\hline RazPerdlog & -0.10611 & 0.01963 & -5.404 & $2.43 \mathrm{e}-07$ & $* * *$ \\
\hline
\end{tabular}

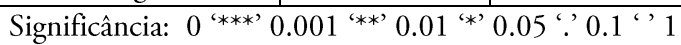

Residual standard error: 0.2031 on 154 degrees of freedom ( 2 observations deleted due to missingness).

Multiple R-squared: 0.7235, Adjusted R-squared: 0.7145 .

F-statistic: 80.58 on 5 and $154 \mathrm{DF}$, p-value: $<2.2 \mathrm{e}-16$.

Texto recebido em 17 de dezembro de 2019. Aprovado em 24 de julho de 2020. 